\title{
Endoscopic thyroid surgery requires surgeons, patient candidacy \& neural monitoring
}

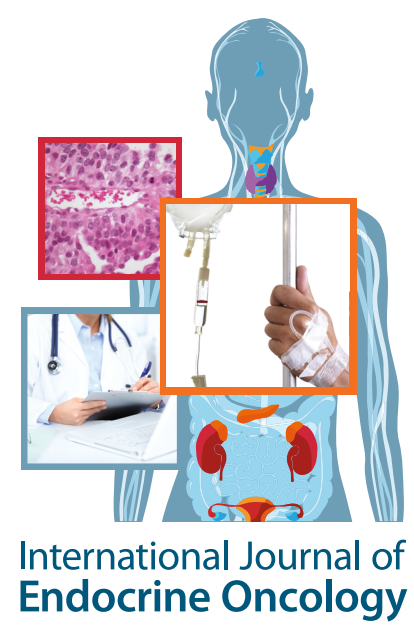

Hui Sun ${ }^{1} \&$ Gianlorenzo Dionigi*,2

${ }^{1}$ Jilin Provincial Key Laboratory of Surgical Translational Medicine, China Japan Union Hospital of Jilin University, Division of Thyroid Surgery, Changchun City, Jilin Province, PR China

2Department of Human Pathology in Adulthood \& Childhood 'G. Barresi', Division for Endocrine \& Minimally Invasive Surgery,

University Hospital G. Martino, University of Messina, Via C. Valeria 1, 98125, Messina, Italy

*Author for correspondence: Tel..: +390902 212637; gdionigi@unime.it

\section{" Surgeons cannot apply a new approach without a perfect grasp of the laryngeal nerves [7]. This would be in contrast with commonly performed routine, conventional surgery."}

First draft submitted: 19 January 2018; Accepted for publication: 22 February 2018; Published online: 09 April 2018

Keywords: endoscopy • neural monitoring • thyroid surgery

Thyroid surgery has a long tradition [1]. The first thyroid interventions were performed at the end of the 18th century [2]. In recent decades, thyroid surgery has become a common intervention with calculable, low intraoperative risks $[3,4]$.

In thyroid surgery, several alternative, increasingly complex procedures as cervical minimally invasive (partially endoscopically assisted), extracervical endoscopic (partially robot assisted) and transoral approaches have been developed over the last 25 years [1-4].

A clear definition for minimally invasive thyroid surgery is not found in the literature [5]. Purely endoscopic or video-assisted cervical surgical procedures as well as minimally invasive open thyroid surgery are characterized by short incision lengths and largely fulfill the requirements of minimally invasive surgery [6]. Other videoscopic procedures (retroauricular, transaxillary and transmamillary) are primarily aimed at completely avoiding a scar on the neck $[7,8]$. Extracervical access requires long preparation distances, which is more invasive. Therefore, the term alternative access to thyroid resection seems to be more applicable for the large number of surgical techniques, as a minimization of the access and operation trauma cannot be regularly ascertained $[9,10]$.

All of these alternative access methods aim at optimizing the cosmetic result [11].

The desire for an optimal cosmetic result should not be paramount to patient safety [12]. With regards to patient safety, the same results must be achieved here as with the very standardized and low-complication rate of open thyroid surgery [13].

Since traditional thyroid surgery is an established, safe surgery with minimal complication rates, alternative surgical methods should be legitimately and continually critically evaluated $[14,15]$.

The indication for the application of alternative access methods differs in principle not from that for the conventional operation [1-3].

Nonetheless, a corresponding experience in endocrine surgery, endoscopic/robotic principles, procedures and accessories and highly patient selection, taking into account thyroid volumes and underlying pathology, are important prerequisites [7].

Only a few alternative methods (minimally invasive video-assisted thyroidectomy [MIVAT], transaxillary robotic thyroidectomy) can currently be considered in responsible, experienced hands as a useful complement to conventional thyroid surgery for a highly selected patient population [3,4]. There are sufficient data for MIVAT that this procedure can be carried out safely in selected hands in selected patients. Some alternative methods, such as MIVAT, are a useful supplement to conventional thyroid surgery for a highly selected patient population [1-5]. 
The use of alternative approaches to thyroid resection requires a corresponding experience in conventional thyroid surgery and appropriate patient selection, taking into account thyroid volume, nodule size and underlying pathology [16]. For all alternative approaches, the same principles apply with regard to indication and avoidance of complications as with conventional surgical procedures. The inclusion and exclusion criteria for the choice of procedure are not yet clearly defined [16].

All alternative surgical procedures require careful patient selection as well as the strict indication and have proven especially in the resection of benign, small-volume findings. A required incision length of $1.5-3 \mathrm{~cm}$ for MIVAT defines a thyroid volume of up to $30 \mathrm{ml}$ or a nodule diameter of up to $30 \mathrm{~mm}$. These values are largely applicable to the other alternative approaches [17].

General contraindications for alternative access are considered to be a large goiter with compression symptoms, advanced thyroid carcinomas, recurrent interventions or previous radiation in the operating area [4].

In the German guideline for the operative therapy of malignant thyroid diseases the alternative access routes are not mentioned $[5,17,18]$. This implies that, according to German experts in proven thyroid malignancies, the conventional operation via Kocher collar incision is the only alternative [5,17,8]. Cosmetic aspects should definitely lag behind the oncological quality of the intervention. This opinion does not find a worldwide consensus as numerous publications from the Asian region and our European neighbors prove [1-3].

Surely, in all areas of surgery, an expansion of surgical indications is closely linked to the surgeon's growing expertise [15-18].

A prospective Korean study was used to identify the institutional learning curve for transaxillary endoscopic nonrobotic lobectomy (L) and total thyroidectomy (T) [19]. The studied parameters of the learning curve were duration of operation, number of lymph nodes obtained, transient hypocalcemia and transient vocal cord paresis. $\mathrm{T}$ was only started after appropriate experience in the $\mathrm{L}$. A total of $95 \%$ of the 300 thyroid operations were due to thyroid microcarcinomas. Total operating time of the Ls was $102 \mathrm{~min}$, which fell significantly after the first 60 operations. T operation times were $131 \mathrm{~min}(\mathrm{p}<0.05 \mathrm{~T}$ vs $\mathrm{L})$ and reduced after the first 38 cases. With regard to the number of lymph nodes obtained, transient hypocalcaemia and vocal fold paresis, there was no dependence on the number of $\mathrm{L}$ or $\mathrm{T}$ performed. The study is interesting, because for the first time numbers to the learning curve transaxillary endoscopic $\mathrm{L}$ and $\mathrm{T}$ are presented [17-19]. The number of lymph nodes harvested and the frequency of transient hypocalcemia and vocal cord paresis were independent of the number of transaxillary operations since they are largely determined by experience in conventional thyroid surgery [19]. As expected, the duration of transaxillary resection decreased as the frequency of surgery increased, as did the number of patients. After initially about $140 \mathrm{~min}$ for the $\mathrm{L}$ and $150-200 \mathrm{~min}$ for the T, a mean time of $100 \mathrm{~min}$ for the $\mathrm{L}$ was reached after the first 60 operations, a mean time of $130 \mathrm{~min}$ for the $\mathrm{T}$ after the first 40 cases. The average operation time achieved for the more difficult $\mathrm{T}$ after a smaller number of cases than after $\mathrm{L}$ is explained by the fact that the $\mathrm{T}$ was only started when there was enough experience with the L. The present study concludes that unilateral and bilateral transaxillary endoscopic nonrobotic thyroid surgery achieves an operative time approximately equivalent to conventional thyroid surgery after the first 100 operations [19].

Finally, with regards to patient safety, the same results must be achieved here as with the very standardized and low-complication of open thyroid surgery [8]. With numerous institutions beginning to perform endoscopic thyroidectomy, there is an increased interest in new devices that may facilitate training and the surgical procedure itself, reduce morbidity and conversion rate to the conventional open technique [20]. Endoscopic or robotic thyroid surgery may entail a higher risk of lesions in both the recurrent laryngeal nerve (RLN) and the superior laryngeal nerve. The presupposition is that, without a perfect understanding of the laryngeal nerves in terms of identification and intraoperative functional assessment, a surgeon can apply neither the new endoscopic nor the robotic approaches. [3,18]. This would be in contrast with the commonly open procedures; it will be a step back [20]. Thyroid surgeon should transfer the same safety principles applied on conventional surgery in endoscopic thyroidectomy [17]. Any further new remote or direct approach will have to be in the same security area of open procedures for RLN management [17]. Endoscopic and robotic thyroidectomy are a technique that demands full control of nerve function. Surgeons cannot apply a new approach without a perfect grasp of the laryngeal nerves [7]. This would be in contrast with commonly performed routine, conventional surgery. It would be a backwards step. In order to avoid adverse outcomes, intraoperative neural monitoring (IONM) has been developed to assess, in real-time, the function of the RLN and superior laryngeal nerve [20]. Endoscopy requires IONM to achieve net benefit of any new approach to the thyroid gland [20]. 
New surgical techniques should only be introduced in controlled trials with standardized IONM use and protocols reviewed by an ethics committee [17,18].

\section{Financial \& competing interests disclosure}

The authors have no relevant affiliations or financial involvement with any organization or entity with a financial interest in or financial conflict with the subject matter or materials discussed in the manuscript. This includes employment, consultancies, honoraria, stock ownership or options, expert testimony, grants or patents received or pending, or royalties.

No writing assistance was utilized in the production of this manuscript.

\section{Open access}

This work is licensed under the Creative Commons Attribution 4.0 License. To view a copy of this license, visit http://creativecommons.org/licenses/by/4.0/

\section{References}

1. Fu J, Luo Y, Chen Q et al. Transoral endoscopic thyroidectomy: review of 81 cases in a single institute. J. Laparoendosc. Adv. Surg. Tech. A. doi: 10.1089/lap.2017.0435 (2018) (Epub ahead of print).

2. Dionigi G, Chai YJ, Tufano RP, Anuwong A, Kim HY. Transoral endoscopic thyroidectomy via a vestibular approach: why and how? Endocrine 59(2), 275-279 (2018).

3. Anuwong A, Ketwong K, Jitpratoom P, Sasanakietkul T, Duh QY. Safety and outcomes of the transoral endoscopic thyroidectomy vestibular approach. JAMA Surg. 153(1), 21-27 (2018).

4. Materazzi G, Fregoli L, Papini P, Bakkar S, Vasquez MC, Miccoli P. Robot-assisted transaxillary thyroidectomy (RATT): a series appraisal of more than 250 cases from Europe. World J. Surg. 42(4) 1018-1023 (2017).

5. Dralle H, Musholt TJ, Schabram J et al. German Association of Endocrine Surgeons practice guideline for the surgical management of malignant thyroid tumors. Langenbecks Arch. Surg. 398(3), 347-375 (2013).

6. Anuwong A, Sasanakietkul T, Jitpratoom P et al. Transoral endoscopic thyroidectomy vestibular approach (TOETVA): indications, techniques and results. Surg. Endosc. 32(1), 456-465 (2018).

7. Dionigi G, Tufano RP, Russell J, Kim HY, Piantanida E, Anuwong A. Transoral thyroidectomy: advantages and limitations. J. Endocrinol. Invest. 40(11), 1259-1263 (2017).

8. Chai YJ, Chung JK, Anuwong A et al. Transoral endoscopic thyroidectomy for papillary thyroid microcarcinoma: initial experience of a single surgeon. Ann. Surg. Treat. Res. 93(2), 70-75 (2017).

9. Russell JO, Clark J, Noureldine SI et al. Transoral thyroidectomy and parathyroidectomy - a North American series of robotic and endoscopic transoral approaches to the central neck. Oral Oncol. 71, 75-80 (2017).

10. Anuwong A, Kim HY, Dionigi G. Transoral endoscopic thyroidectomy using vestibular approach: updates and evidences. Gland Surg. 6(3), 277-284 (2017).

11. Dionigi G, Kim HY, Wu CW. Neuromonitoring in endoscopic and robotic thyroidectomy. Updates Surg. 69(2), 171-179 (2017).

12. Dionigi G, Bacuzzi A, Lavazza M et al. Transoral endoscopic thyroidectomy: preliminary experience in Italy. Updates Surg. 69(2), 225-234 (2017).

13. Lee HY, Lee JY, Dionigi G, Bae JW, Kim HY. The efficacy of intraoperative neuromonitoring during robotic thyroidectomy: a prospective, randomized case-control evaluation. J. Laparoendosc. Adv. Surg. Tech. A. 25(11), 908-914 (2015).

14. Dionigi G, Alesina PF, Barczynski $M$ et al. Recurrent laryngeal nerve injury in video-assisted thyroidectomy: lessons learned from neuromonitoring. Surg Endosc. 26(9), 2601-2608 (2012).

15. Dionigi G, Duran-Poveda M. New approaches in thyroid surgery: is there an increased risk of nerve injury? Ann. Surg. Oncol. 18 (Suppl. 3), S252-S253 (2011).

16. Dionigi G, Boni L, Duran-Poveda M. Evolution of endoscopic thyroidectomy. Surg. Endosc. 25(12), 3951-3952, author reply 3953 (2011).

17. Maurer E, Wächter S, Bartsch DK. Alternative approaches in thyroid surgery. Chirurg 88(8), 675-681 (2017).

18. Dralle H, Thanh PN. Learning curve for transaxillary endoscopic thyroidectomy. Chirurg 86(6), 606 (2015).

19. Kwak HY, Kim SH, Chae BJ, Song BJ, Jung SS, Bae JS. Learning curve for gasless endoscopic thyroidectomy using the trans-axillary approach: CUSUM analysis of a single surgeon's experience. Int. J. Surg. 12(12), 1273-1277 (2014).

20. Sung ES, Lee JC, Kim SH, Shin SC, Jung DW, Lee BJ. Development of an attachable endoscopic nerve stimulator for intraoperative neuromonitoring during endoscopic or robotic thyroidectomy. Otolaryngol. Head Neck Surg. 158(3), 465-468 (2017) 
